\title{
Effectiveness of Lumbar Facet Joint Nerve Blocks in Chronic Low Back Pain: A Randomized Clinical Trial
}

\author{
Laxmaiah Manchikanti, MD*, Vidyasagar Pampati, M Sc\#, Cyrus E. Bakhit, MD**, \\ Jose J. Rivera,MD"\#, Carla D. Beyer, RN`, Kim S. Damron, RN`, and Renee C. Barnhill, RN`
}

This randomized clinical trial was designed to determine the effectiveness of therapeutic lumbar facet joint nerve blocks.

Two hundred patients were evaluated with controlled diagnostic blocks for the presence of facet joint mediated pain. Eighty four patients, or $42 \%$ were determined to have lumbar facet joint mediated pain. These patients were randomly allocated into two groups: Group I receiving therapeutic injections with local anesthetic and Sarapin ${ }^{\circledR}$, and Group II receiving therapeutic injections with a mixture of local anesthetic, Sarapin, and methyl prednisolone. A total of 73 patients were treated with medial branch blocks under fluoroscopy.

Results showed that patients underwent multiple procedures over a period of $2 \frac{1}{2}$ years. The mean number of procedures or interventions was $2.5 \pm 0.09$ from 1 to 3 months, whereas it was $4 \pm 0.13$ for 4 to 6 months, $6.1 \pm$ 0.21 for 7 to 12 months, and $8.4 \pm 0.31$ for 13 to 32 months.
Cumulative significant relief with one to three injections was $100 \%$ up to 1 to 3 months, $82 \%$ for 4 to 6 months, $21 \%$ for 7 to 12 months, and $10 \%$ after 12 months, with a mean relief of $6.5 \pm 0.76$ months. There was significant improvement noted in overall health status with improvement not only in pain relief, but also with physical, functional, and psychological status, as well as return-to-work status.

In conclusion, the results of this study demonstrate that medial branch blocks with local anesthetic and Sarapin, with or without steroids, are a cost effective modality of treatment, resulting in improvement in pain status, physical status, psychological status, functional status and return to work.

Keywords: Low back pain, facet joint nerve blocks, Sarapin, methyl prednisolone
The prevalence of persistent low back pain secondary to the involvement of lumbosacral facet joints has been described in controlled studies variably as $15 \%$ (1), $36 \%$ (2), 40\% (3), $42 \%$ (4) and 45\% (5). Even though evidence is lacking for the diagnosis of the so called lumbar facet syndrome (1-9), a preponderance of evidence supports the existence of lumbar facet joint pain (1-25). However, there is no shortage of detractors questioning the existence of facet joint mediated pain (26-30).

From the Pain Management Center of Paducah, Paducah, Kentucky. *Medical director, "Statistician, "\#Interventional pain physician, and ${ }^{\bullet}$ Clinical coordinators at the Pain Management Center of Paducah. **Interventional pain physician at the Roanoke Pain Center in Roanoke, VA. Address correspondence: Laxmaiah Manchikanti, MD, 2831 Lone Oak Road, Paducah, Kentucky 42003. Email: drm@apex.net
Similar to the controversial nature of the epidemiology and clinical significance of facet joint pain, significant controversy also surrounds various treatments utilized in the management of chronic low back pain emanating from lumbosacral facet joints. Long term therapeutic benefit for facet joint pain has been reported with use of three types of interventions. These include intra-articular injections $(6,8,10,15-20,22,23,31-33)$, medial branch blocks (2, 6, 3234 ), and neurolysis of medial branches by means of either radiofrequency, chemical neurolysis, or cryoneurolysis (6, $8,20,34-41)$. The long term therapeutic benefit of intraarticular injections of facet joints has been equivocal (6, 8, $10,14-20)$, whereas the literature lacks any descriptions of long term benefits of medial branch blocks (2, 6, 32-34); and some have (34-39) promoted radiofrequency medial branch neurotomy as the best treatment for low back pain emanating from facet joints. However, the results of radiofrequency neurolysis also have been highly variable, with various authors reporting $35 \%$ to $87 \%$ long term relief in positive studies $(34,35-39)$. Recent controlled studies of Van Kleef et al (36) and Dreyfuss et al (35) attempted to 
prove that radiofrequency is the only proven treatment for facet joint mediated pain. However, the results are rather inconclusive. Van Kleef et al (36) studied 31 patients in a double blind fashion with 16 patients in the control group and 15 in the treatment group with reports of initial relief in $67 \%$, which declined to $66 \%$ by three months and $47 \%$ by six months. However, they (36) also reported that in the control group 38\% initially, 25\% at three months and $9 \%$ at 6 months obtained significant relief of their pain. In contrast, Dreyfuss et al (35) in a prospective study, utilizing a sophisticated and complicated technique in a rigorous investigation, reported $87 \%$ of the patients as having good long-term relief. However, Dreyfuss et al (35) reported that weekly average visual analog scale (VAS) scores (0 to 10) were 5.1, with a range of 2.0 to 9.0 thus indicating that there were a number of patients who scored less than 5 on VAS of average pain. In addition, these patients were recruited through advertisement and most patients were functional and working, providing a patient population different from that seen in a chronic pain management center, which is a low-functional status, nonworking population that has psychological problems.

While intra-articular injection therapy, with or without steroids, has been widely studied for lumbar facet joint mediated pain, there are only four studies evaluating the effectiveness of medial branch blocks (2, 32-34) and they were employed mainly for diagnostic purposes. Manchikanti et al (2) studied the diagnostic validity and therapeutic value of lumbar facet joint nerve blocks with or without adjuvant agents and utilized either only local anesthetic, a mixture of local anesthetic and Sarapin ${ }^{\circledR}$ (High Chemical, Levittown, PA), or a mixture of local anesthetic, Sarapin, and methyl prednisolone. They reported that in double-block positive patients the mean relief with the second confirmatory block utilizing either plain bupivacaine, bupivacaine with Sarapin, or bupivacaine with Sarapin and methyl prednisolone showed a mean relief in days of $20.6 \pm 3.97,29.6 \pm 4.86$, and $49.8 \pm 9.4$ days, ranging from 3 to 98 days, 12 to 98 days, and 5 to 160 days, respectively, which indicated that utilization of adjuvant agents for medial branch blocks may be a viable option in producing long term relief. It was also shown that medial branch blocks were as equally effective as intra-articular facet joint injections $(32,33)$.

The duration of relief with therapeutic medial branch blocks with Sarapin with or without methyl prednisolone has not been studied, even though an earlier study (2) demonstrated significant therapeutic effect with facet joint nerve blocks with the addition of either Sarapin or Sarapin and methyl prednisolone. In addition, radiofrequency neurolysis at times is not acceptable to patients, and not approved by insurers, and the feasibility of performing this procedure is becoming increasingly difficult due to the new regulations with non availability of site of service for many patients in the United States (42-47).

Hence, this study was designed and undertaken to evaluate various issues of controversy and lack of information. The issues explored included duration of relief with therapeutic medial branch blocks with local anesthetic and Sarapin, with or without steroid, in a prospective, randomized fashion evaluating significant pain relief, overall health status, drug intake, and cost effectiveness. This study was an extension of an earlier study (4), that evaluated the prevalence of lumbar facet joint pain in a consecutive series of patients with chronic low back pain using controlled diagnostic blocks.

\section{METHODS}

The study was designed to evaluate 200 consecutive patients seen in one private pain management practice in a non-university setting. Of all the patients presenting for pain management to this center, 212 patients with a chief complaint of low back pain, with or without lower extremity pain, were randomly allocated to one physician. During this time, the physician evaluated 396 new patients. Patients younger than 18 years or older than 90 years, those who exhibited neurological deficits, those who had pain for less than 6 months, those who had responded to conservative management, or those who had undergone neural blockade in the past were excluded. Initial management of these patients has been described previously (2).

Of the 200 patients included in the study, 34\% were evaluated with unilateral blocks, 66\% with bilateral blocks, 92\% with levels from L3 to L5, 5\% from L2 to L5, and 3\% from L1 to L5. All patients underwent single blocks with lidocaine; 127 , or $64 \%$, of the patients reported a definite positive response to lidocaine blocks. Confirmatory blocks with bupivacaine were performed in all 127 patients, with 84 patients, ie, $42 \%$ of the total sample or $66 \%$ of the lidocaine-positive group, reporting definite response with improvement in their pain, with a false positive rate of $37 \%$ (Table 1 ).

Following completion of the diagnostic phase, all 84 patients required treatment at various intervals after return of the pain following the second diagnostic block. These 
Table 1. Comparison of the results of single blocks (lidocaine) and double blocks (lidocaine and bupivacaine)

\begin{tabular}{lccc}
\hline Prevalence: $42 \%$ & Sensitivity: $100 \%$ & Specificity: $63 \%$ & False positive rate: $37 \%$ \\
\hline Single blocks & \multicolumn{3}{c}{ Double blocks } \\
\hline & Positive & Negative \\
Positive & 84 & 43 \\
Negative & 0 & 73 \\
\hline
\end{tabular}

patients were randomly allocated into two groups, Group I receiving therapeutic injections with a local anesthetic and Sarapin and Group II receiving therapeutic injections with a mixture of local anesthetic, Sarapin and methyl prednisolone. Seventy three patients were enrolled in the study. The remaining 11 patients, or $13 \%$, were excluded for the following reasons:

- Three patients in Group I were stopped treatment due to a decision by a third party carrier.

- $\quad$ One patient in Group 1 stopped treatments due to multiple medical problems and hospitalization unrelated to the treatment.

- Six patients in Group I and one patient in Group II decided to undergo radiofrequency thermo-neurolysis, as the option was provided.

Thus, there were 32 patients in Group I and 41 patients in Group II.

The study period lasted from January of 1998 to June of 2000, thus providing $21 / 2$ years of management and follow up. All charts were reviewed, and patients were contacted by one of the two physicians who were not involved in their treatment during the treatment period and at the end of the study. The evaluation included data collection as to the variables of age, gender, duration of pain in months, nature of onset, height, weight, and history of previous surgical interventions; the number of injections received by each patient in each group; the quality and duration of pain relief; overall health status in pre and posttreatment phases; psychological status in pre and posttreatment phases; narcotic intake in pre and post-treatment periods; and employment and work status in pre and post-treatment periods. The quality of pain relief was characterized as less than $50 \%$ relief, or greater than $50 \%$ relief. Pain relief greater than 50\% was considered significant, and these patients were characterized as successful with "significant pain relief."
All procedures were performed by one physician in an ambulatory surgery setting, either in a sterile operating room or a treatment room. All medial branch blocks were performed under fluoroscopy, with patients in the prone position. The blocks, performed under appropriate monitoring with intravenous (IV) access and mild sedation with midazolam, were performed at each of the medial branches at L1 through L4 and L5 dorsal ramus using a 3.5-inch spinal needle, \#22-gauge. Each nerve was infiltrated with 0.5 to $1 \mathrm{~mL}$ of a mixture of local anesthetic consisting of either $0.5 \%$ lidocaine or $0.25 \%$ bupivacaine mixed with equal volumes of Sarapin and $1 \mathrm{mg}$ of methyl prednisolone/mL of the mixture. In Group 1, no methyl prednisolone was utilized. The blocks were performed on the ipsilateral side in patients with unilateral pain, or bilateral in patients with bilateral or midline (axial) pain.

Following the blocks, the patients were discharged home. With a return visit, each patient was evaluated for amount of relief of pain on the basis of a verbal pain scale, perceived physical health by the patient and physician, perceived mental health by the physician and patient, and perceived functional status by the patient and physician. Patients were also evaluated on narcotic intake with each visit. All the features were evaluated on each visit by a treating physician and at the end of the treatment by a physician not involved in treatment, and the data were tabulated. Any potential complications were also evaluated at each visit.

Demographic features of age, mode of onset of pain, work status, history of surgery, and other historical features were obtained from the patient history and recorded. The patient's age was calculated from his/her birth date, whereas duration of pain was calculated based on the patient's memory of the onset of the pain to the closest month, when available. Pain characteristics were obtained from the history, comprehensive pain questionnaire, and pain diagram. Pain rating was obtained from a 10-point verbal 
pain rating scale. Average pain, physical health, mental health, and functional status, were determined from multiple sources including patient description of the pain, and patient perception of physical health, mental health and functional status, as well as objective evaluations performed with psychological evaluation and range-of-motion evaluation and ability to function and carry on important activities they were unable to perform prior to the intervention. Psychological status was determined by a psychological questionnaire, as well as psychological evaluation utilizing MCMI-II and Beck’s Depression Inventory. Major depression, generalized anxiety disorder, and somatization disorder were determined from these tests. Symptom magnification was determined utilizing a set of signs and symptoms that included multiple items: strategy to control symptoms, control over environment, overt pain behavior, pain rating, pain diagram, nonphys- iologic symptoms and signs, presence or absence of objective signs, laboratory evidence, coefficient of variation with functional testing, cooperation with evaluation and presence or absence of somatization as determined by MCMI-II. Narcotic intake was determined as none, mild, moderate, and heavy based on the dosage, frequency and class of drug. Intake of class IV narcotics, ie., propoxyphene napsylate (Darvocet ${ }^{\circledR}$ ), pentazocine hydrochloride (Talwin ${ }^{\circledR}$ ), tramadol hydrochloride (Ultram ${ }^{\circledR}$ ), up to a maximum of four times, or hydrocodone twice or less per day, was considered as mild; intake of class III narcotics, ie. hydrocodone, up to four times as moderate; and intake of class II narcotics ie. oxycodone, morphine, meperidine, transdermal fentanyl, and methadone in any dosage was considered as heavy. Employment and work status divided into employed, unemployed, housewife, disabled, and retired also determined from the pretreatment and post-

Table 2. Patient characteristics

\begin{tabular}{|c|c|c|c|c|}
\hline & & Group I & Group II & Total (Groups I and II) \\
\hline Number of patients & & 32 & 41 & 73 \\
\hline \multirow[t]{2}{*}{ Gender } & Male & $34 \%(11)$ & $44 \%(18)$ & $40 \%(29)$ \\
\hline & Female & $66 \%(21)$ & $56 \%(23)$ & $60 \%(44)$ \\
\hline \multirow[t]{4}{*}{ Age (yrs.) } & Range & $22-80$ & $22-85$ & $22-85$ \\
\hline & $<65$ & $78 \%(25)$ & $83 \%(34)$ & $81 \%(59)$ \\
\hline & $>65$ & $22 \%(7)$ & $17 \%(7)$ & $19 \%(14)$ \\
\hline & Mean + SEM & $46.3+2.86$ & $47.2+2.69$ & $46.8+1.95$ \\
\hline \multirow[t]{2}{*}{ Weight (lbs.) } & Range & $126-340$ & $97-310$ & $97-340$ \\
\hline & Mean + SEM & $204+11.24$ & $174+7.70$ & $187+6.74$ \\
\hline \multirow[t]{2}{*}{ Height (inches) } & Range & $61-77$ & $66-77$ & $61-77$ \\
\hline & Mean + SEM & $66.6+0.75$ & $67.2+0.64$ & $66.9+0.47$ \\
\hline \multirow[t]{3}{*}{ Mode of onset of pain } & Occupational & $16 \%(5)$ & $12 \%(5)$ & $14 \%(10)$ \\
\hline & Non-occupational & $53 \%(17)$ & $30 \%(12)$ & $40 \%(29)$ \\
\hline & Non-traumatic & $31 \%(10)$ & $58 \%(24)$ & $46 \%(34)$ \\
\hline \multirow[t]{4}{*}{$\begin{array}{l}\text { Duration of pain } \\
\text { (years)Mean + SEM }\end{array}$} & $<1$ & $25 \%(8)$ & $24 \%(10)$ & $25 \%(18)$ \\
\hline & $1-4$ & $16 \%(5)$ & $20 \%(8)$ & $18 \%(13)$ \\
\hline & $>4$ & $59 \%(19)$ & $56 \%(23)$ & $57 \%(42)$ \\
\hline & Mean + SEM & $1.83+0.31$ & $1.70+0.29$ & $1.73+0.20$ \\
\hline Postlumbar laminectomy & & $31 \%(10)$ & $17 \%(7)$ & $3 \%(17)$ \\
\hline
\end{tabular}

( ): Number of patients SEM: Standard error of mean 
Table 3. Details of multiple procedures

\begin{tabular}{lcccccc}
\hline \multirow{2}{*}{ Number of procedures } & \multicolumn{2}{c}{ Group I } & \multicolumn{2}{c}{ Group II } & \multicolumn{2}{c}{ Total (Group I and II) } \\
\cline { 2 - 7 } & Number & Percent & Number & Percent & Number & Percent \\
\hline Two & 32 & $100 \%$ & 41 & $100 \%$ & 73 & $100 \%$ \\
Three & 28 & $88 \%$ & 40 & $98 \%$ & 68 & $93 \%$ \\
Four & 25 & $78 \%$ & 39 & $95 \%$ & 64 & $88 \%$ \\
Five & 22 & $69 \%$ & 37 & $90 \%$ & 59 & $81 \%$ \\
Six & 21 & $66 \%$ & 34 & $83 \%$ & 55 & $75 \%$ \\
Seven & 17 & $53 \%$ & 27 & $66 \%$ & 44 & $60 \%$ \\
Eight & 10 & $31 \%$ & 19 & $46 \%$ & 29 & $40 \%$ \\
Nine & 9 & $28 \%$ & 12 & $29 \%$ & 21 & $29 \%$ \\
Ten & 7 & $22 \%$ & 8 & $20 \%$ & 15 & $21 \%$ \\
\hline
\end{tabular}

treatment work status. Only employed and unemployed patients were considered to be eligible for employment, whereas disabled patients and patients over 65 were considered not employable; however, data were tabulated if any of these patients returned to work. The data were evaluated and confirmed by one of the two physicians who were not performing the blocks and treating the patients.

Data were recorded on a database using Microsoft ${ }^{\circledR}$ Access ${ }^{\circledR}$; the SPSS Version 9.0 statistical package was used to generate the frequency tables, and the chi-squared statistic was used to test the significant difference between groups. Fisher's Exact Test was used wherever expected value was less than five. Student's t test was used to test mean difference between groups. Results were considered statistically significant if the p value was less than 0.05 .

\section{RESULTS}

\section{Patient Characteristics}

Demographic data are shown in Table 2, with no significant differences noted between groups in terms of gender, age, weight, height, mode of onset of pain, duration of pain, and history of previous surgical intervention.

\section{Injection Characteristics}

Table 3 illustrates the details of patients undergoing multiple procedures over a period of $21 / 2$ years. Sixty percent of the patients underwent seven procedures, which was reduced to $40 \%$ for eight procedures, $29 \%$ for nine procedures, and $21 \%$ for ten procedures. As shown in Table 4, the mean number of interventions was $2.5 \pm 0.09$

Table 4. Mean episodes of medial branch blocks

\begin{tabular}{lccc}
\hline & $\begin{array}{c}\text { Group I } \\
\text { Mean + SEM }\end{array}$ & $\begin{array}{c}\text { Group II } \\
\text { Mean + SEM }\end{array}$ & $\begin{array}{c}\text { Total (Groups I and II) } \\
\text { Mean + SEM }\end{array}$ \\
\cline { 2 - 4 } 1-3 Months & $2.6+0.14(32)$ & $2.4+0.11(41)$ & $2.5+0.09(73)$ \\
4-6 Months & $4.0+0.24(32)$ & $4.0+0.15(41)$ & $4.0+0.13(73)$ \\
7-12 Months & $6.0+0.38(25)$ & $6.2+0.24(39)$ & $6.1+0.21(64)$ \\
13-32 months & $8.6+0.61(17)$ & $8.3+0.34(28)$ & $8.4+0.31(45)$ \\
\hline
\end{tabular}

( ): Number of patients SEM: Standard error of mean 
Table 5. Comparison significant relief (> 50\%) with each injection by group in weeks

\begin{tabular}{lcccccc}
\hline Injection & \multicolumn{2}{c}{ Group I } & \multicolumn{2}{c}{ Group II } & \multicolumn{2}{c}{ Total (Groups I and II) } \\
\cline { 2 - 7 } number & Mean + SEM & Range & Mean + SEM & Range & Mean + SEM & Range \\
\hline One & $7.2+2.06(32)$ & $2-65$ & $5.2+0.38(41)$ & $2-13$ & $6.1+0.93(73)$ & $2-65$ \\
Two & $11.9+3.14(32)$ & $3-78$ & $9.1+1.77(41)$ & $3-78$ & $10.3+1.71(73)$ & $3-78$ \\
Three & $15.1+4.21(28)$ & $0-86$ & $10.4+1.78(40)$ & $4-78$ & $12.3+2.03(68)$ & $0-86$ \\
Four & $9.7+1.88(25)$ & $2-52$ & $9.6+0.46(39)$ & $4-17$ & $9.7+0.78(64)$ & $2-52$ \\
Five & $8.6+0.71(22)$ & $2-13$ & $14.6+3.11(37)$ & $3-102$ & $12.4+1.99(59)$ & $2-102$ \\
Six & $14.5+3.43(21)$ & $0-65$ & $10.5 *+0.75(34)$ & $1-30$ & $12.0+1.39(55)$ & $0-65$ \\
Seven & $21.0 *+5.55(17)$ & $0-78$ & $10.7+0.55(27)$ & $4-17$ & $14.7+2.26(44)$ & $0-78$ \\
Eight & $8.8+1.48(10)$ & $0-13$ & $15.6+3.74(19)$ & $6-78$ & $13.3+2.55(29)$ & $0-78$ \\
Nine & $9.4+1.45(9)$ & $0-13$ & $12.2+2.15(12)$ & $9-30$ & $11.0+1.38(21)$ & $0-30$ \\
Ten & $14.4+2.60(7)$ & $9-26$ & $10.0 *+1.00(8)$ & $9-17$ & $12.1+1.40(15)$ & $9-26$ \\
\hline ( ): Number of patients SEM: Standard error of mean * indicates significant difference between groups
\end{tabular}

from 1 to 3 months, whereas it was $4.0 \pm 0.13$ for 4 to 6 months, $6.1 \pm 0.21$ for 7 to 12 months, and $8.4 \pm 0.31$ for 13 to 32 months. There were no significant differences noted between the groups with multiple procedures, or mean episodes of medial branch blocks..

\section{Pain Relief}

The duration of significant pain relief associated with each injection by members of the two groups for 10 consecutive injections is illustrated in Table 5. There were no significant differences noted between the groups for each injection except with the sixth and seventh injections. The relief ranged from 2 to 65 weeks with the first injection to 9 to 26 weeks with the tenth injection, with an overall range of 2 to 102 weeks. However, differences were noted from injection to injection. In Group I, significant differences were noted in the duration of relief with first injections compared to the seventh injection ( $p=0.017$ ), fourth injection compared to seventh injection $(p=0.036)$, fifth injection compared to seventh injection $(\mathrm{p}=0.044)$, and eighth injection compared to seventh injection ( $\mathrm{p}=0.048)$. In Group II, significant differences were noted with injections three, five, six, seven and eight compared to the first injection ( $p=0.007,0.008,0.000,0.0000 .024$ ), injections three, five, six, seven, and eighth compared to the fourth injection $(\mathrm{p}=0.038)$.

Cumulative significant relief was also evaluated with one to three injections in months (Table 6). This showed that

Table 6. Cumulative relief (>50\%) with one to three (1-3) injections

\begin{tabular}{cccc}
\hline Cumulative relief in months & Group I & Group II & Total (Groups I and II) \\
\hline$<3$ & $100 \%(32)$ & $100 \%(41)$ & $100 \%(73)$ \\
$4-6$ & $75 \%(24)$ & $88 \%(36)$ & $82 \%(60)$ \\
$7-12$ & $25 \%(8)$ & $17 \%(7)$ & $21 \%(15)$ \\
$>12$ & $16 \%(5)$ & $5 \%(2)$ & $10 \%(7)$ \\
Mean + SEM & $7.5+1.54$ & $5.7+0.59$ & $6.5+0.76$ \\
\hline
\end{tabular}

( ): Number of patients SEM: Standard error of mean 


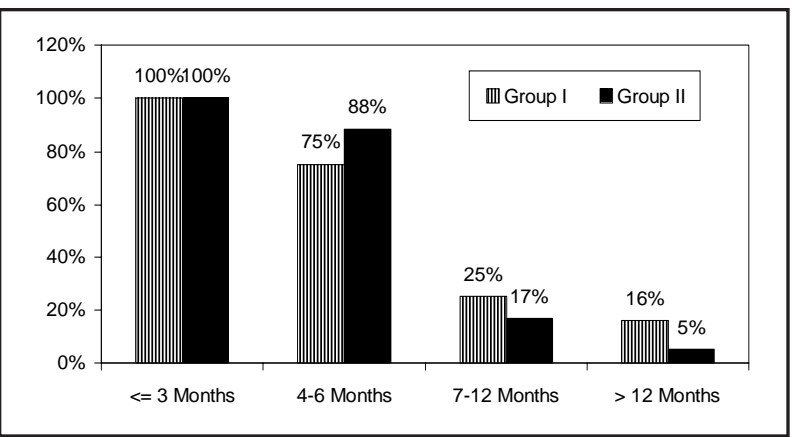

Fig. 1. Cumulative relief (>50\%) with one to three (1-3) injections

$100 \%$ of the patients experienced significant relief in both groups for 3 months, whereas this was variable after three months with a decrease to $82 \%$ total at 4 to 6 months, $21 \%$ at 7 to 12 months, and $10 \%$ after 12 months, with a mean relief of $6.5 \pm 0.76$ months. There was no significance difference noted between groups. Fig. 1 illustrates cumulative relief in both groups.

\section{Overall Health Status}

Comparison of overall health status prior to the treatment and after the treatment as shown in Table 7 demonstrated that average pain, physical health, mental health, and functional status, which were all evaluated by a 10-point verbal scale, showed significant decrease in mean pain levels from $7.7 \pm 0.09$ to $3.4 \pm 0.14$; and significant improvement in physical health from $4.9 \pm 0.14$ to $6.9 \pm 0.14$, in mental health from $4.5 \pm 0.13$ to $6.6 \pm 0.5$, and in functional status from $3.6 \pm 0.11$ to $5.5 \pm 0.14$. Fig. 2 demonstrates the change seen in all the patients.

Similar to the overall health status, psychological status was also evaluated, with evaluation of depression, anxiety, somatization, and symptom magnification. However, even

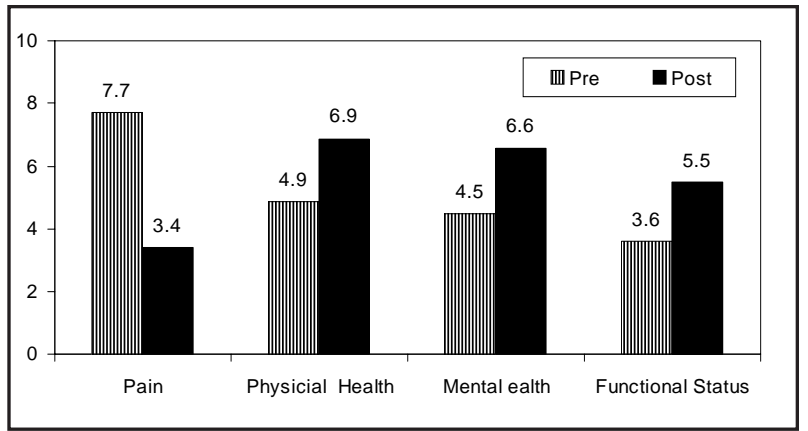

Fig. 2. Change in pain status, physical health, mental health, and functional status post treatment compared to pre treatment

though there was clinical improvement seen in all parameters, with reduction in depression, anxiety, somatization and symptom magnification in both groups, significant differences were noted only for change in somatization disorder, which was seen in $49 \%$ of patients prior to the treatment and was reduced to $30 \%$ after treatment (Table 8).

\section{Narcotic Intake}

Narcotic intake was also compared to pretreatment and post-treatment in all patients in both groups (Table 9). Clinical improvement with reduction in narcotic intake was seen in all patients, even though significant differences were only noted in patients taking heavy amounts of narcotics prior to treatment, with reduction from $30 \%$ to $17 \%$ in the posttreatment period. Similarly, mild intake of narcotics also increased from $14 \%$ to $27 \%$, indicating the transfer of a significant number of patients to the mild intake group. Fig. 3 illustrates the change in narcotic intake.

\section{Employment Status}

Employment or work status is shown in Table 10. The patients who were employed and unemployed were con-

Table 7. Comparison of overall health status pre and post treatment

\begin{tabular}{lllllll}
\hline & \multicolumn{2}{l}{ Group I } & \multicolumn{3}{c}{ Group II } & \multicolumn{2}{c}{ Total (Groups I and II) } \\
\cline { 2 - 7 } & Pre & Post & Pre & Post & Pre & Post \\
\cline { 2 - 7 } Average pain & $7.6+0.13$ & $3.5^{*}+0.26$ & $7.7+0.12$ & $3.3^{*}+0.15$ & $7.7+0.09$ & $3.4^{*}+0.14$ \\
Physical health & $4.6+0.18$ & $6.7^{*}+0.25$ & $5.1+0.19$ & $7.1^{*}+0.15$ & $4.9+0.14$ & $6.9^{*}+0.14$ \\
Mental health & $4.2+0.18$ & $6.3^{*}+0.30$ & $4.7+0.18$ & $6.7^{*}+0.14$ & $4.5+0.13$ & $6.6^{*}+0.15$ \\
Functional status & $3.6+0.17$ & $5.3^{*}+0.24$ & $3.7+0.15$ & $5.7^{*}+0.16$ & $3.6+0.11$ & $5.5^{*}+0.14$ \\
\hline
\end{tabular}

* Indicates significant difference between pre and post treatment SEM: Standard error of mean 
Table 8. Psychological status of patients in both groups pre and post treatments

\begin{tabular}{|c|c|c|c|c|c|c|c|}
\hline \multirow{2}{*}{\multicolumn{2}{|c|}{ Psychological status }} & \multicolumn{2}{|c|}{ Group I } & \multicolumn{2}{|c|}{ Group II } & \multicolumn{2}{|c|}{ Total (Groups I and II) } \\
\hline & & Pre & Post & Pre & Post & Pre & Post \\
\hline \multirow{2}{*}{ Depression } & No & $19 \%(6)$ & $28 \%(9)$ & $27 \%(11)$ & $42 \%(17)$ & $23 \%(17)$ & $36 \%(26)$ \\
\hline & Yes & $81 \%(26)$ & $72 \%(23)$ & $73 \%(30)$ & $58 \%(24)$ & $77 \%(56)$ & $64 \%(47)$ \\
\hline \multirow{2}{*}{$\begin{array}{l}\text { Generalized } \\
\text { anxiety } \\
\text { disorder }\end{array}$} & No & $28 \%(9)$ & $37 \%(12)$ & $24 \%(10)$ & $39 \%(16)$ & $26 \%(19)$ & $38 \%(28)$ \\
\hline & Yes & $72 \%(23)$ & $63 \%(20)$ & $76 \%(31)$ & $61 \%(25)$ & $74 \%(54)$ & $62 \%(45)$ \\
\hline \multirow{2}{*}{$\begin{array}{l}\text { Somatization } \\
\text { disorder }\end{array}$} & No & $59 \%(19)$ & $72 \%(23)$ & $44 \%(18)$ & $68 \% *(28)$ & $51 \%(37)$ & $70 \% *(51)$ \\
\hline & Yes & $41 \%(13)$ & $18 \%(9)$ & $56 \%(23)$ & $32 \%(13)$ & $49 \%(36)$ & $30 \%(22)$ \\
\hline \multirow{2}{*}{$\begin{array}{l}\text { Symptom } \\
\text { magnification }\end{array}$} & No & $72 \%(23)$ & $81 \%(26)$ & $66 \%(27)$ & $78 \%(32)$ & $68 \%(50)$ & $79 \%(58)$ \\
\hline & Yes & $28 \%(9)$ & $19 \%(6)$ & $34 \%(14)$ & $22 \%(9)$ & $32 \%(23)$ & $21 \%(15)$ \\
\hline
\end{tabular}

( ): Number of patients * Indicates significant difference between pre and post treatment

sidered as candidates for future employment or continued employment. Housewives, disabled patients, and patients over 65 who were retired were considered not eligible for future employment. However, a total of three patients, one from Group 1 and two from Group 2, from the disabled category became employed during the treatment period and continued to be employed at the end of the treatment period. As shown in Table 10, there were 10 patients, or $13 \%$, employed prior to treatment, whereas 18 patients, or $25 \%$, were unemployed prior to the treatment; this increased to $29 \%$, or 21 patients, being employed at the end of treatment, and reduced the unemployed patient population from 18 patients, or $25 \%$, to four patients, or $5 \%$, essentially indicating that some of the patients were employed whereas some were disabled. The increase in employment and reduction in unemployment were significant. The number of disabled patients also increased from 30 to 33 , or from $41 \%$ to $45 \%$; however, this was not significant. Fig. 4 illustrates comparison of employment status prior to and following the treatment.

\section{Cost Effectiveness}

Cost effectiveness was analyzed, as shown in Table 11, for both groups. The total cost was calculated for all procedures, including complications, in all patients. The number of weeks with significant relief was calculated as 2399, with a mean relief of $11.4 \pm 1.10$ weeks per procedure for Group I, 3085 weeks with a mean relief of $10.2 \pm 0.63$ weeks per procedure for Group II; and 5484 weeks with a mean relief of $10.7 \pm 0.58$ weeks per procedure for both groups combined. Total expenditures were calculated from net collections, or the patient's expenses for the outpatient surgical center and physician fees as incurred by the in-

Table 9. Comparison of narcotic intake in pre and post treatments

\begin{tabular}{lcccccc}
\hline \multirow{2}{*}{ Narcotic intake } & \multicolumn{2}{c}{ Group I } & \multicolumn{2}{c}{ Group II } & \multicolumn{2}{c}{ Total (Groups I and II) } \\
\cline { 2 - 7 } & Pre & Post & Pre & Post & Pre & Post \\
\hline None & $9 \%(3)$ & $25 \%(8)$ & $15 \%(6)$ & $19 \%(8)$ & $12 \%(9)$ & $22 \%(16)$ \\
Mild & $13 \%(4)$ & $22 \%(7)$ & $15 \%(6)$ & $32 \% *(13)$ & $14 \%(10)$ & $27 \% *(20)$ \\
Moderate & $50 \%(16)$ & $34 \%(11)$ & $39 \%(16)$ & $34 \%(14)$ & $44 \%(32)$ & $34 \%(25)$ \\
Heavy & $28 \%(9)$ & $19 \%(6)$ & $32 \%(13)$ & $15 \% *(6)$ & $30 \%(22)$ & $17 \% *(12)$ \\
\hline
\end{tabular}

$(\mathrm{):} \mathrm{Number} \mathrm{of} \mathrm{patients} *$ Indicates significant difference between pre and post treatment 


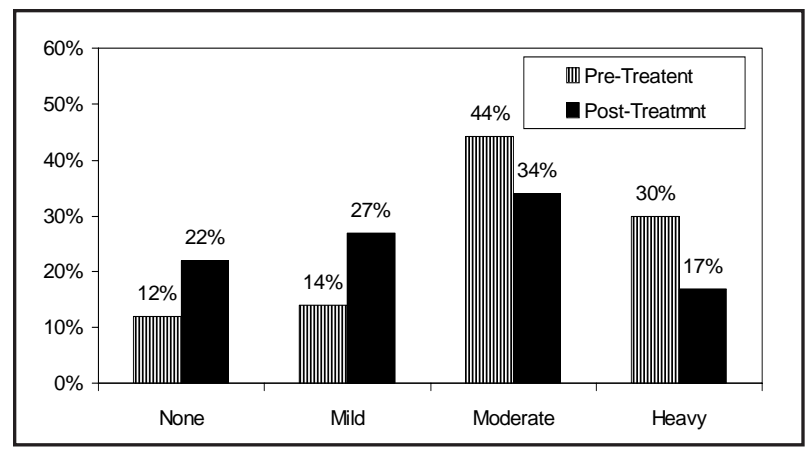

Fig. 3. Change in narcotic intake

surer and/or the patient. The total cost per procedure was \$678, \$740, and \$714 for Groups I and II and a combination of Groups I and II respectively. The total cost for 32 patients in Group I, 41 patients in Group II, and 73 patients total was $\$ 142,286$, $\$ 222,769$ and $\$ 365,085$ respectively. The total number of procedures were 210 for Group I, 310 for Group II, and 511 combined, with an average number of procedures per patient of $6.6 \pm 0.55$ for Group I, $7.3 \pm 0.34$ for Group II, and $7.0 \pm 0.31$ for both groups combined. Further calculations showed that significant pain relief was provided with a cost-per-1-week improvement of quality of life in Group I of \$59, in Group II of \$72, and of \$67 for both groups combined. Calculation of these cost figures with conversion to a 1-year improvement of quality of life showed a cost of \$3084 for Group I, \$3755 for Group II, and \$3461 for all patients, with no significant difference noted between the groups. However, this cost effectiveness analysis did not take into consideration the patients return to work and various other benefits; nor did the cost benefit ratio consider the money spent outside therapy for drugs or other types of treatments. In addition, the cost of the diagnostic blocks was also not included in this analysis.

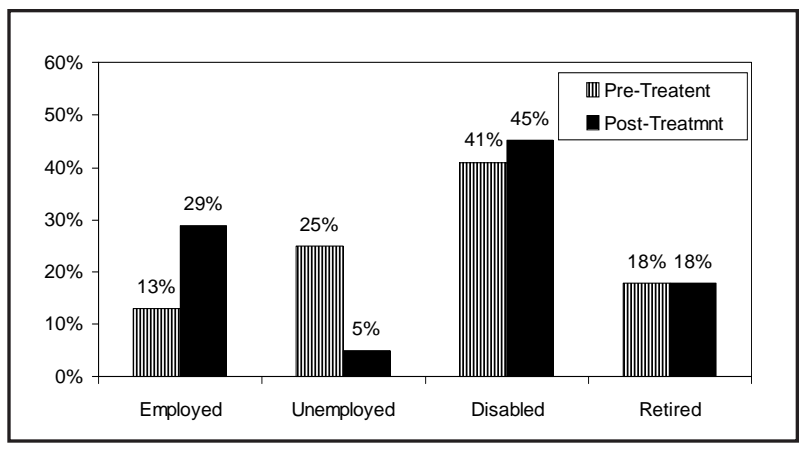

Fig. 4. Employment or work status of patients pre and post treatments

\section{Complications}

None of the various types of complications, including infection, rash, reaction to drugs, epidural or subarachnoid blockade, postlumbar puncture headache, and/or weight gain, were observed in any of the patients.

\section{DISCUSSION}

Neural blockade in the management of facet joint pain has been applied since 1976, with reports by Mooney and Robertson (10). Long term therapeutic benefit has been reported from injection of corticosteroids into facet joints (14-20, 31). The literature describing the effectiveness of intra-articular injections in the lumbar spine is abundant even though only five controlled clinical trials offer data on the use of intra-articular injections $(14,18,19,32$, 33). In contrast, while the role of medial branch blocks in the diagnosis of facet joint pain has been well described and considered superior to intra-articular local anesthetic

Table 10. Employment or work status of patients in both groups pre and post treatments

\begin{tabular}{lcccccc}
\hline \multirow{2}{*}{$\begin{array}{l}\text { Employment and } \\
\text { work status }\end{array}$} & \multicolumn{2}{c}{ Group I } & \multicolumn{2}{c}{ Group II } & \multicolumn{2}{c}{ Total (Groups I and II) } \\
\cline { 2 - 7 } Employed & Pre & Post & Pre & Post & Pre & Post \\
\hline Unemployed & $10 \%(3)$ & $31 \% *(10)$ & $17 \%(7)$ & $27 \%(11)$ & $13 \%(10)$ & $29 \% *(21)$ \\
Housewife & $34 \%(11)$ & $9 \%(3)$ & $17 \%(7)$ & $2 \%(1)$ & $25 \%(18)$ & $5 \% *(4)$ \\
Disabled & $3 \%(1)$ & $3 \%(1)$ & $2 \%(1)$ & $2 \%(1)$ & $3 \%(2)$ & $3 \%(2)$ \\
Over $>65$ (Retired) & $19 \%(6)$ & $19 \%(6)$ & $17 \%(7)$ & $17 \%(7)$ & $18 \%(13)$ & $18 \%(13)$ \\
\hline
\end{tabular}

( ): Number of patients * indicates significant difference between groups 
Table 11. Analysis of cost-effectiveness of facet joint nerve blocks in managing facet joint mediated pain

\begin{tabular}{lccc}
\hline & Group I & Group II & Total \\
\hline Number of patients & 32 & 41 & 73 \\
Total number of procedures & 210 & 301 & 511 \\
Number of treatments per patient (mean + SEM) & $6.6+0.55$ & $7.3+0.34$ & $7.0+0.31$ \\
Visits with significant relief (>50\%) & $98 \%$ & $100 \%$ & $99 \%$ \\
Number of weeks with significant relief for all patients & 2399 & 3085 & 5484 \\
in the study in weeks & & & \\
Significant relief in weeks per procedure & $11.4+1.10$ & $10.2+0.63$ & $10.7+0.58$ \\
(mean + SEM) & & & \\
Total Cost (\$) & 31,356 & 54,598 & 85,957 \\
Physician & 110,930 & 168,198 & 279,128 \\
Facility & 142,286 & 222,769 & 365,085 \\
Total & & & \\
Cost per procedure (\$) & 149 & 181 & 168 \\
Physician & 528 & 559 & 546 \\
Facility & 678 & 740 & 714 \\
Total & 59 & 72 & 67 \\
Cost for 1-week improvement of quality of life (\$) & 3084 & 3755 & 3461 \\
Cost for 1-year improvement of quality of life (\$) & & & \\
\hline SEM: Standard error of mean & & & \\
& & &
\end{tabular}

blocks for diagnostic purposes, (1-8, 48-52), but for therapeutic purposes, the literature is sparse; with no reports from controlled studies. Results from the few existing studies indicate that facet joint injections and medial branch blocks are of equal value $(32,33)$. Marks et al (32) studied 86 patients with refractory chronic low back pain who were randomly assigned to receive either facet joint injections or medial branch blocks, using local anesthetic and steroid. Using methylprednisolone acetate, $20 \mathrm{mg}$, along with lidocaine $1 \%, 1.5 \mathrm{~mL}$, the results indicate good to excellent relief in 38\% of patients following facet joint injection (32). However, good to excellent response was seen in only $43 \%$ of patients receiving facet joint injection and $46 \%$ of the patients with medial branch blocks in the first two weeks (32). At one month follow up, 35\% of the patients with facet joint injection and $21 \%$ of the patients with medial branch blocks reported good relief (32). At three month follow up, only $22 \%$ of the patients with injections showed good to excellent relief, and only $14 \%$ achieved the same level of relief following medial branch blocks (32). In another prospective, randomized, single blinded sequential analysis of 66 patients, Nash (33) reported comparable effectiveness of the medial branch blocks with intra-articular injection of local anesthetic and steroids utilizing 2\% lidocaine $1 \mathrm{~mL}$ and $0.5 \%$ bupivacaine $1 \mathrm{~mL}$ and $20 \mathrm{mg}$ of methylprednisolone; and for each medial branch blocks, treating utilizing $2 \%$ lidocaine $1 \mathrm{~mL}$ and $0.5 \%$ bupivacaine $1 \mathrm{~mL}$. The two treatments were equally effective but were disappointing in their therapeutic effect. A total of $58 \%$ of patients in each group demonstrated significant pain relief at one month follow up. In another study, North et al (34) used diagnostic facet blocks and incorporated assessment by a disinterested third party. Following diagnostic medial branch blocks, $42 \%$ of the patients reported at least $50 \%$ relief of pain. Among 40 patients who underwent temporary blocks but did not undergo radiofrequency denervation, $13 \%$ reported relief by at least $50 \%$ at long term follow up with mean interval of 3.2 years (34). Manchikanti et al 
(2) showed that the total relief with two diagnostic blocks utilizing either Xylocaine or bupivacaine, with Sarapin, with or without methyl prednisolone, have shown that a mean relief in days of $20.6 \pm 3.97$ to $49.8 \pm 9.40$ days; with a range of 3 to 160 days which showed that Sarapin, as well as methyl prednisolone, both added to therapeutic efficiency.

Comparison of results of lumbar medial branch blocks in the present study with intra-articular injections and radiofrequency neurolysis is illustrated in Table 12 . The medial branches in the present study with one to three interventions were shown to provide relief in $100 \%$ of patients for up to three months, in $82 \%$ of the patients for from 4 to 6 months, in 21\% of patients for from 7 to 12 months and in $10 \%$ for over 12 months; whereas, when the interventions were calculated throughout the period with one to ten interventions, this study showed a higher percentage of the patients experiencing significant relief at all levels of the evaluation. The studies, which were determined as positive for intra-articular injections, $(15-17,19$, 20,22 ) provided relief in $28 \%$ to $94 \%$ of patients for less than 1 month, $28 \%$ to $62 \%$ of patients for 1 to 3 months, $14 \%$ to $56 \%$ of patients for 4 to 6 months, $8 \%$ to $38 \%$ of patients for 7 to 12 months, and finally, $8 \%$ to $28 \%$ of patients over 12 months. The studies, which have been determined as positive for radiofrequency neurotomy (20, 3439 ), showed initial relief of less than one month in $42 \%$ to $87 \%$ of patients, for one to three months in from $42 \%$ to $87 \%$ of the patients, for 4 to 6 months in $42 \%$ to $87 \%$ of patients, for 7 to 12 months in $42 \%$ to $87 \%$ of patients and for over 12 months in $10 \%$ to $87 \%$ of patients. Thus, the results of the present study with medial branch blocks are comparable to both radiofrequency neurolysis, as well as intra-articular injections with one to three injections for up to 6 months; whereas continued repeat interventions were comparable to radiofrequency neurotomy even after 12 months.

The current study is the first prospective study to have treated patients with facet joint mediated pain confirmed with controlled diagnostic blocks utilizing therapeutic medial branch blocks with two types of adjuvant agents, namely Sarapin and methyl prednisolone. In addition, the current study differs in several respects from all previous studies. First, this is the first study evaluating the therapeutic effects of medial branches. Second, this is the third study in the literature which has evaluated relief obtained with therapeutic medial branch blocks with adjuvants (2, 32). Third, it is the only study in which multiple subjective and objective outcome measures were recorded during a prolonged follow up period of 18 to 32 months.

In this study both groups of patients, with or without steroids, but with Sarapin, showed significant improvement in all parameters. Further, this study also showed that medial branch blocks are cost effective compared to numerous other modalities of treatments in managing low back pain (Fig. 5). Thus, it appears that the medial branch blocks are a reasonable alternative to therapeutic intraarticular injections or radiofrequency neurotomy (Table 12). The cost effectiveness of medial branch blocks, with or without steroids, was \$3,461 per 1-year improvement of quality of life (Table 11).

Table 12. Comparison of results of lumbar medial branch blocks with intra-articular injections and radiofrequency neurolysis

\begin{tabular}{|c|c|c|c|c|c|c|}
\hline \multirow{2}{*}{ Treatment modality } & \multirow{2}{*}{ References } & \multicolumn{5}{|c|}{ Pain relief } \\
\hline & & $<1$ Month & 1-3 Months & 4-6 Months & 7-12 Months & > 12 Months \\
\hline $\begin{array}{l}\text { Medial branch blocks } \\
\text { (one to three injections) }\end{array}$ & Present study & $100 \%$ & $100 \%$ & $82 \%$ & $21 \%$ & $10 \%$ \\
\hline $\begin{array}{l}\text { Medial branch blocks } \\
\text { (one to ten injections) }\end{array}$ & Present study & $100 \%$ & $100 \%$ & $100 \%$ & $95 \%$ & $81 \%$ \\
\hline Intra-articular injections & $\begin{array}{l}15-17,19, \\
20,22\end{array}$ & $28 \%-94 \%$ & $28 \%-62 \%$ & $14 \%-56 \%$ & $8 \%-38 \%$ & $8 \%-28 \%$ \\
\hline $\begin{array}{l}\text { Radiofrequency } \\
\text { neurotomy }\end{array}$ & $20,34-39$ & $42 \%-87 \%$ & $42 \%-87 \%$ & $42 \%-87 \%$ & $42 \%-87 \%$ & $10 \%-87 \%$ \\
\hline
\end{tabular}




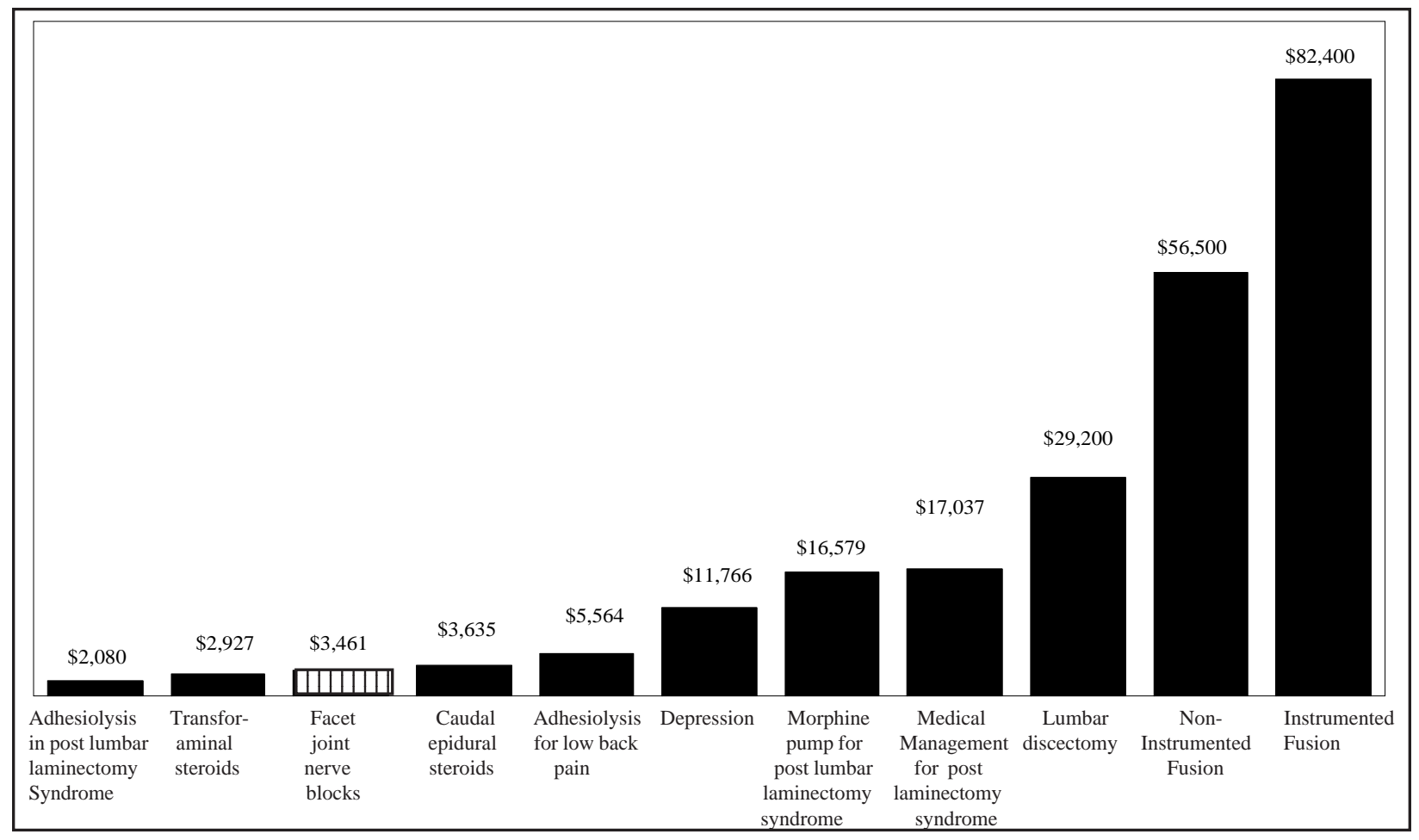

Figure 5. Cost effectiveness of various types of therapy in managing medical conditions including chronic low back pain. Adapted and modified from Kuntz et al (81), Malter et al (76), Muller-Schwefe et al (77), Lave et al (85), and Manchikanti et al (78-80).

Corticosteroids have been utilized in the management of chronic low back pain by injecting them into the epidural space since $1952(53,54)$. Subsequently, when steroid administration seemingly was effective for the management of low back pain in sciatica, others followed the concept and adapted the treatment, not only for epidural administration but also for other types of neural blockade, including facet-joint injections $(6,55)$. In addition, over a period of time, it also became apparent that the injection of steroids into joints could relieve certain types of joint pain, encouraging investigators and practitioners to use these drugs for management of facet-joint pain $(10,55)$. In addition, the rationale for steroid usage in neural blockade is primarily based on the benefits of neural blockade, including the pain relief which outlasts by hours, days, and sometimes weeks, the transient pharmacologic action of other adjuvant agents such as local anesthetics and others.

Sarapin is a suspension of powdered sarracenia purpurin (pitcher plant) in alkaline solution. Though commonly used in some quarters, it is unknown to many. The value of Sarapin in relieving pain of neurologic origin was reported by Bates and Judovich in $1931(56,57)$. However, clinical investigations on this unique product are lacking. Sarapin has been reported to cause no motor weakness following injection of the peripheral nerve; it also does not cause or affect loss of touch, pressure, pinprick, or temperature sensibility and has an excellent risk/benefit ratio. Controlled studies with procaine, saline, and water show prolonged duration of effect in favor of the pitcher-plant preparation (57). The basis of the pitcher plant derivative, or Sarapin, was explained by experiments performed on the action potentials of the saphenous nerve of the cat, which showed that the C-fiber potential was completely obliterated by pitcher-plant extract after emersion in the solution for about 5 minutes. Researchers theorize that the distillate contained an unidentified biological substance that potentiates the action of the ammonium ion. Modest but significant benefits were demonstrated with diagnostic blocks utilizing Sarapin, which preserved not only diagnostic validity, but also provided therapeutic value (2).

This study was prospective and randomized; however, it was not blinded; thus, it may be criticized for its nonblinded nature, as both the physician and patients were aware of the type of treatment, as well as the potential adverse effects. However, once again, the issues of ethics, feasibility, cost, and reliability pose challenges to a 
double-blind trial, which theoretically presents the gold standard (58-63). However, a recent analysis by Concato and coworkers (64) analyzing numerous reports for five clinical topics, found that well-designed observational studies do not systematically overestimate the magnitude of effects of treatments as compared with those in randomized, controlled trials on the same topic. Although this is not to undermine the importance of randomized, double-blinded, controlled studies, flaws can exist in a study design or analysis, both in open as well as blinded trials (65-69). In addition, lack of randomization, rather than blinding of the treatment which supposedly overestimates the treatment effect described as $41 \%$ for lack of randomization, and $17 \%$ for a non-blinded trial (70).

The study may also be criticized for lack of outside thirdparty review; however, the physicians involved in the evaluation included not only the treating physician, but also a physician who was not involved in providing care to these patients.

The cost effectiveness analysis may also be criticized for various reasons. In the present environment confusion abounds over what is meant by the term cost effectiveness. Cost effectiveness analysis has taken on an increasingly large role in health care policy debates about various interventions for managing low back pain. Growing health-care costs and productivity losses, disappointing treatment results, and changing beliefs in health and pain have led to this increasing concern about the amount of money spent on chronic low back pain. In recent years, more and more studies in the field of the management of chronic low back pain have been incorporating cost issues in their analysis (71-81). While economic evaluation designs describe cost minimization analysis (CMA), cost benefit analysis (CBA), cost effectiveness analysis (CEA), or cost utility analysis (CUA), in chronic low back pain CEA and CUA would be the most appropriate methods to use, since in these studies the effects are measured in natural units and quality of life. The outcome measures used in CEA studies in chronic pain research mainly include outcomes, such as disability days saved; pain-free days: or improved quality of life, etc., (71), evaluation of the quality of life, which is also known as functional status, health status, or health-related quality of life; wellbeing of the patient; satisfaction with care and health service utilization/economic analysis, and medical findings (82). The quality-of-life assessment is designed to evaluate the patient's ability to function in his/her own world. Physical function measures the ability to perform physical activities such as walking, climbing stairs or carrying things. Evaluation focuses on the patient's major perceived functional impairments/improvement in areas such as playing with children/grandchildren, having sexual relations, returning to work, going to school, homemaking, or performing other activities of daily living. Quality of life also measures social functioning, which determines whether health problems affect normal social activities, such as seeing friends or participating in group activities. Cost of inpatient chronic pain programs ranges from $\$ 17,000$ to $\$ 25,000$, and the cost of outpatient treatment programs ranges from $\$ 7,000$ to $\$ 10,000$ (83). In addition, chronic pain patients may incur health-care bills in excess of \$20,000 annually for repetitive and, in some cases, redundant diagnostic workups, physical therapy, psychological interventions, and drugs. In a recent study, Guo and colleagues (84) estimated that back pain accounted for 150 million lost workdays in the United States every year, which worked out to be about $\$ 14$ billion in wage costs alone. The study showed that the magnitude of the back pain problem is so large that even a $1 \%$ reduction in overall prevalence could considerably reduce morbidity and save billions of dollars. The cost effectiveness of lumbar discectomy for the treatment of herniated intervertebral discs has been based on the conclusion that surgery increased the average quality-adjusted life expectancy by 0.43 years during the decade following treatment compared to conservative treatment, a result comparable to extending a healthy life by 5 months (76). Malter et al (76) also concluded that, for carefully selected patients with herniated discs, surgical discectomy is a cost effective treatment at a discounted cost of $\$ 12,000$ per discectomy, or $\$ 29,000$ per life year adjusted for quality. Kuntz et al (81) studied the cost effectiveness of fusion with and without instrumentation for patients with degenerative spondylolisthesis and spinal stenosis. They (81) showed that laminectomy with a noninstrumented fusion costs $\$ 56,500$ per quality-adjusted year of life versus laminectomy without fusion. The cost effectiveness ratio of instrumented fusion compared with noninstrumented fusion was $\$ 3,112,800$ per quality-adjusted year of life (81). However, they also stated that if the proportion of patients experiencing symptom relief after instrumented fusion was $90 \%$, as compared with $80 \%$ for patients with noninstrumented fusion, then the cost effectiveness ratio of instrumented fusion compared with noninstrumented fusion would be $\$ 82,400$ per quality-adjusted year of life. Mueller-Schwefe and colleagues (77), in evaluating cost effectiveness of intrathecal therapy for pain secondary to failed back surgery syndrome, compared alternative therapies for achieving a defined outcome, reporting the cost of medical management to be $\$ 17,037$ per year or $\$ 1,420$ per month. They 
(77) also showed that intrathecal morphine delivery resulted in lower cumulative 60-month costs of $\$ 16,579$ per year, and \$1,382 per month. The cost effectiveness evaluation for blind interlaminar, fluoroscopically directed caudal or transforaminal epidural injections for the management of low back pain showed the cost effectiveness of caudal epidural steroids to be $\$ 3,635$ and transforaminal steroids to be $\$ 2,927$ per year, with a stark contrast with blind interlaminar lumbar epidural steroid injections at \$6,024 per year (78). Similarly, the cost effectiveness of percutaneous nonendoscopic adhesiolysis and hypertonic saline neurolysis for 1-day and 2-day protocol was demonstrated to be $\$ 5,564$ and $\$ 8,127$, respectively, for improvement of 1 year of quality of life for patients with chronic low back pain nonresponsive to numerous other modalities of treatment (79). Similarly, cost effectiveness with nonendoscopic adhesiolysis was shown to be \$2,028 per year, whereas it was $\$ 7,020$ with endoscopic adhesiolysis in postlumbar laminectomy patients (80). Thus, cost effective analysis of this evaluation with medial branch blocks demonstrating cost for 1 year of improvement in the quality of life is similar to various investigations in the past with neural blockade but also significantly better than improvement with intrathecal morphine delivery, lumbar laminectomy, lumbar laminectomy with or without instrumented fusion (Fig. 5). In addition, interpretation of the current results should be placed in the context of not only other interventional procedures, but also surgery and other modalities of treatments. Lave et al (85) demonstrated the cost effectiveness of medical treatment of depression management as \$11,766 per year of quality-adjusted life. It was also shown that a simple reduction of diastolic pressure from 110 to $90 \mathrm{mmHg}$ was achieved at a cost of $\$ 16,330$ for a 60 -year old man in 1974 (82). Total hip arthroplasty for osteoarthritis of the hip costs $\$ 61,000$ per quality-adjusted year of life gained (86). Lumbar discectomy for the treatment of herniated intervertebral discs cost $\$ 39,500$ per quality-adjusted year of life gained $(76,81)$; coronary artery bypass grafting for patients with triple-vessel coronary artery disease and severe left ventricular function cost $\$ 41,800$ per quality-adjusted year of life gained (87) and surgery to repair a 4-cm abdominal aortic aneurysm costs $\$ 21,800$ per quality-adjusted year of life gained (88). Therefore, medial branch blocks for patients suffering with chronic facet joint mediated pain have a cost effectiveness ratio not only in the same approximate range as that of other well-accepted modalities of treatment in managing chronic low back pain, but, also well within reasonable limits for present-day cost effective management of other medical conditions. (Fig. 5). Thus far, none of the previous studies has addressed the consequence of repeat medial branch blocks. This study has demonstrated that this modality of treatment is not only effective, but also without complications.

\section{CONCLUSION}

Medial branch blocks are an effective modality of treatment in managing lumbar facet joint mediated pain confirmed by controlled diagnostic blocks. Medial branch blocks with or without steroid but with local anesthetic and Sarapin are effective in providing significant pain relief, improvement in functional status, improvement in overall psychological status, and return to work. Medial branch blocks also exert some effect on the patient's state of depression, anxiety, and symptom magnification; while these blocks show significant effect in decrease of somatization. Hence, it is concluded that medial branch blocks are an effective modality of treatment in managing chronic lumbar facet joint mediated pain.

\section{REFERENCES}

1. Schwarzer AC, Aprill CN, Derby R et al. Clinical features of patients with pain stemming from the lumbar zygapophysial joints. Is the lumbar facet syndrome a clinical entity? Spine 1994; 19:1132-1137.

2. Manchikanti L, Pampati RR, Fellows B et al. The diagnostic validity and therapeutic value of medial branch blocks with or without adjuvants. Cur Rev Pain 2000; 4:337-344.

3. Schwarzer AC, Wang S, Bogduk N et al. Prevalence and clinical features of lumbar zygapophysial joint pain. A study in an Australian population with chronic low back pain. Am Rheum Dis 1995; 54:100-106.

4. Manchikanti L, Pampati VS, Fellows B et al. The inability of the clinical picture to characterize pain from facet joints. Pain Physician 2000; 3:158-166.

5. Manchikanti L, Pampati VS, Pakanati RR et al. Prevalence of facet joint pain in chronic low back pain. Pain Physician 1999; 2:59-64.

6. Manchikanti L. Facet joint pain and the role of neural blockade in its management. Cur Rev Pain 1999; 3:348358.

7. Bogduk N. International spinal injection society guidelines for the performance of spinal injection procedures. Part 1. Zygapophysial joint blocks. Clin J Pain 1997; 13:285-302.

8. Dreyfuss PH, Dreyer SJ, Herring SA. Contemporary concepts in spine care. Lumbar zygapophysial (facet) joint injections. Spine 1995; 20:2040-2047.

9. Schwarzer AC, Derby R, Aprill CN et al. Pain from the lumbar zygapophysial joint. A test of two models. J Spinal Disord 1994; 7:331-336. 
10. Mooney V, Robertson J. The facet syndrome. Clin Orthop 1976, 115:149-156.

11. McCall IW, Park WM, O’Brien JP. Induced pain referral from posterior elements in normal subjects. Spine 1979; 4:441-446.

12. Marks R. Distribution of pain provoked from lumbar facet joints and related structures during diagnostic spinal infiltration. Pain 1989; 39:37-40.

13. Fukui S, Ohseto K, Shiotani M et al. Distribution of referral pain from the lumbar zygapophyseal joints and dorsal rami. Clin J Pain 1997; 13:303-307.

14. Carette S, Marcoux S, Truchon R et al. A controlled trial of corticosteroid injections into facet joints for chronic low back pain. N Engl J Med 1991; 325:10021007.

15. Murtagh FR. Computed tomography and fluoroscopy guided anesthesia and steroid injection in facet syndrome. Spine 1988; 13:686-689.

16. Lau LS, Littlejohn GO, Miller MH. Clinical evaluation of intra-articular injections for lumbar facet joint pain. Med J Aust 1985; 143:563-565.

17. Lippitt AB. The facet joint and its role in spine pain. Management with facet joint injections. Spine 1984; 9:746-750.

18. Lilius G, Laasonen EM, Myllynen P et al. Lumbar facet joint syndrome. A randomized clinical trial. $J$ Bone Joint Surg (Br) 1989; 71:681-684.

19. Lynch MC, Taylor JF. Facet joint injection for low back pain. A clinical study. J Bone Joint Surg (Br) 1986; 68:138-141.

20. Mironer YE, Somerville JJ. Protocol for diagnosis and treatment of facet joint pain syndrome. A modified three-step approach. Pain Digest 1999; 9:188190.

21. Schwarzer AC, Wang SC, O’ Driscoll D et al. The ability of computed tomography to identify a painful zygapophysial joint in patients with chronic low back pain. Spine 1995; 20:907-912.

22. Destouet JM, Gilula LA, Murphy WA. Lumbar facet joint injection: Indication, technique, clinical correlation and preliminary results. Radiology 1982; 145:321-325.

23. Helbig T, Lee CK. The lumbar facet syndrome. Spine 1988; 13:61-64.

24. Revel ME, Listrat VM, Chevalier XJ et al. Facet joint block for low back pain. Identifying predictors of a good response. Arch Phys Med Rehab 1992; 73:824828.

25. Revel M, Poiraudeau S, Auleley GR et al. Capacity of the clinical picture to characterize low back pain relieved by facet joint anesthesia. Proposed criteria to identify patients with painful facet joints. Spine 1998; 23:1972-1977.

26. Jackson RP, Jacobs RR, Montesano PX. Facet joint injection in low back pain. A prospective study. Spine 1988; 13:966-971.
27. Deyo RA. Fads in the treatment of low back pain. $N$ Engl J Med 1991; 325:1038-1040.

28. Jackson RP. The facet syndrome. Myth or reality? Clin Orthop 1992; 279:110-121.

29. Nachemson AL. Newest knowledge of low back pain. A critical look. Clin Orthop 1992; 279:8-20.

30. Nachemson AL, Vingard E. Assessment of patients with neck and back pain: A best-evidence synthesis. In Nachemson AL, Jonsson E (eds). Neck and back pain. The scientific evidence of causes, diagnosis and treatment. Lippincott Williams \& Wilkins, New York, 2000, pp 189-236.

31. Carrera GF. Lumbar facet joint injection in low back pain and sciatica: Preliminary results. Radiology 1980; 137:665-667.

32. Marks RC, Houston T, Thulbourne T. Facet joint injection and facet nerve block: A randomized comparison in 86 patients with chronic low back pain. Pain 1992; 49:325-328.

33. Nash TP. Facet joints: Intra-articular steroids or nerve blocks? Pain Clinic 1990; 3:77-82.

34. North RB, Han M, Zahurak M et al. Radiofrequency lumbar facet denervation: Analysis of prognostic factors. Pain 1994; 57:77-83.

35. Dreyfuss P, Halbrook B, Pauza K et al. Efficacy and validity of radiofrequency neurotomy for chronic lumbar zygapophysial joint pain. Spine 2000; 25:12701277.

36. Van Kleef M, Barendse GAM, Kessels A et al. Randomized trial of radiofrequency lumbar facet denervation for chronic low back pain. Spine 1999; 24:19371942.

37. Schaerer JP. Radiofrequency facet rhizotomy in the treatment of chronic neck and low back pain. Int Surg 1978; 63:53-59.

38. Burton CB. Percutaneous radiofrequency facet denervation. Appl Neurophysiol 1976/77; 39:80-86.

39. Gallagher J, Vadi PLP, Wesley JR. Radiofrequency facet joint denervation in the treatment of low back pain: A prospective controlled double-blind study to assess efficacy. Pain Clinic 1994; 7:193-198.

40. Silvers RH. Lumbar percutaneous facet rhizotomy. Spine 1990; 15:36-40.

41. Brechner T. Percutaneous cryogenic neurolysis of the articular nerves of Luschka. Reg Anesth 1981; 6:1822.

42. Manchikanti L. State of interventional pain medicine. Pain Physician 2000; 3:241-255.

43. Physician Payment Schedule: Proposed Rule. Federal Register, July 17, 2000.

44. Physician Payment Schedule: Final Rule. Federal Register, November 1, 2000.

45. Medicare Program Prospective Payment System for Hospital Outpatient Services; Final Rule: Washington, D.C., Department of Health and Human Services. Health Care Financing Administration, 42 CFR, Parts 412, 413, and 485. 
46. Ambulatory Surgery Center Proposed Rule. Federal Register, June 1998.

47. Jost TS. Medicare and Medicaid financing of pain management. J Pain 2000; 1:183-194.

48. Kaplan M, Dreyfuss P, Halbrook B et al. The ability of lumbar medial branch blocks to anesthetize the zygapophysial joint. Spine 1998; 23:1847-1852.

49. Dreyfus P, Schwarzer AC, Laup et al. Specificity of lumbar medial branch and L5 dorsal ramus blocks: A computed tomography study. Spine 1997; 22:895-902.

50. Lord SM, Barnsley L, Bogduk N. The utility of comparative local anesthetic blocks versus placebo-controlled blocks for the diagnosis of cervical zygapophysial joint pain. Clin J Pain 1995; 11:208213.

51. Barnsley L, Lord S, Bogduk N. Comparative local anesthetic blocks in the diagnosis of cervical zygapophysial joint pain. Pain 1993; 55:99-106.

52. Barnsley L, Bogduk N. Medial branch blocks are specific for the diagnosis of cervical zygapophysial joint pain. Reg Anesth 1993; 18:343-350.

53. Robechhi A, Capra R. L'idrocortisone (composto F) prime esperienze cliniche in campo reumatolgico. Minerva Med 1952; 98:1259-1263.

54. Lievre JA, Bloch-Michel H, Pean G et al. L'hydrocortisone en injection locale. Rev Rhum 1953; 20:310-311.

55. Bogduk N, Christophidis N, Cherry D et al. Epidural use of steroids in the management of back pain. Report of working party on epidural use of steroids in the management of back pain. Canberra National Health and Medical Research Council, Commonwealth of Australia, 1994, pp 1-76.

56. Bates W, Judovich BD. Intractable pain. Anesthesiology 1942; 3:663-672.

57. Judovich BD, Bates W. Pain syndromes. Treatment by paravertebral nerve block. Philadelphia, FA Davis, 1950; pp242-249.

58. Turner JA, Loeser JD, Bell KG. Spinal cord stimulation for chronic low back pain. A systematic literature synthesis. Neurosurgery 1995; 37:1088-1098.

59. Weinstein JN. The tortoise and the hare. Is there a place in spine surgery for randomized trials? Spine 1999; 23:2548-2549.

60. Winter RB. The prospective, randomized, controlled clinical trial in spine surgery. Fact or fiction? Spine 1999; 23:2550-2552.

61. Carey TS. Randomized controlled trials in surgery. An essential component of scientific progress. Spine 1999; 23:2553-2555.

62. Fairbank J. Randomized controlled trials in the surgical management of spinal problems. Spine 1999; 23:2556-2563.

63. Tosteson TD. Point of view. Spine 1999; 24:25622563.

64. Concato J, Shah N, Horwitz RI. Randomized, controlled trials, observational studies, and the hierarchy of research designs. N Engl J Med 2000; 342:18871892.

65. Pocock SJ, Elbourne DR. Randomized trails or observational tribulations? New Engl J Med 2000; 342;1907-1909.

66. Kunz R, Khan KS, Neumayer H. Observational studies and randomized trials. New Engl J Med 2000; 343:1194.

67. Sacks HS. Observational studies and randomized trials. New Engl J Med 2000; 343:1195.

68. Liu PY, Anderson G, Crowley JJ. Observational studies and randomized trials. New Engl J Med 2000; 343:1195.

69. Friedman HS. Observational studies and randomized trials. $N$ Engl J of Med 2000; 343:1195-1996.

70. Schulz KF, Chambers I, Hayes RJ et al. Empirical evidence of bias: Dimensions of methodological quality associated with estimates of treatment effects on controlled trials. JAMA 1995; 273:408-412.

71. Goossens MEJB, Evers SMAA, Vlaeyen JWS et al. Principles of economic evaluation for interventions of chronic musculoskeletal pain. Eur J Pain 1999; 3:343-353.

72. Ferraz MB, Maetzel A, Bombardier C. A summary of economic evaluations published in the field of rheumatology and related disciplines. Arthritis Rheum 1997; 40:1587-1593.

73. Goossens MEJB, Evers SMAA. Economic evaluation of back pain interventions. J Occup Rehab 1997; 7:15-32.

74. Maetzel A, Ferraz MB, Bombardier C. A review of cost-effectiveness analyses in rheumatology and related disciplines. Current Opin Rheumatol 1998; 10:136-140.

75. Davies AR, Doyle MA, Lansky D, et al. Outcomes assessment in clinical settings: a consensus statement on principles and best practices in project management. Jt Comm J Qual Improv 1994;20:6-16

76. Malter AD, Larwon EB, Urban $\mathrm{N}$ et al. Cost-effectiveness of lumbar discectomy for the treatment of herniated intervertebral disc. Spine 1996; 21:10481055.

77. Mueller-Schwefe G, Hassenbusch SJ, Reig E. Costeffectiveness of intrathecal therapy for pain. Neuromodulation 1999; 2:77-84.

78. Manchikanti L, Pakanati RR, Pampati V. Comparison of three routes of epidural steroid injections in low back pain. Pain Digest 1999; 9:277-285.

79. Manchikanti L, Pakanati RR, Bakhit CE et al. Role of adhesiolysis and hypertonic saline neurolysis in management of low back pain. Evaluation of modification of Racz Protocol. Pain Digest 1999; 9:91-96.

80. Manchikanti L, Pakanati RR, Bakhit CE et al. Nonendoscopic and endoscopic adhesiolysis in post lumbar laminectomy syndrome. A one-year outcome study and cost effectiveness analysis. Pain Physician 1999; 2:52-58. 
81. Kuntz K, Snider R, Weinstein J et al. Cost-effectiveness of fusion with and without instrumentation for patients with degenerative spondylolisthesis and spinal stenosis. Spine 2000; 25: 1132-1139.

82. Hopwood M. Outcomes assessment in pain management. In: Abram SE (ed). Pain Management. Churchill-Livingstone, Philadelphia, 1998, pp 14.114.11.

83. Cicala RS, Wright H. Outpatient treatment of patients with chronic pain. Analysis of cost savings. Clin J Pain 1989; 5: 223-226.

84. Guo HR, Tanaka S, Halperin WE et al. Back pain prevalence in US industry and estimates of lost work days. Am J Public Health 1999; 89:1029-1035.

85. Lave JR, Frank RG, Schulberg HC et al. Cost-effectiveness of treatments for major depression in primary care practice. Arch Gen Psychiatry 1998; 55:645-651.
86. Chang RW, Pellissier JM, Hazen GB. A cost-effectiveness analysis of total hip arthroplasty for osteoarthritis of the hip. JAMA 1996; 275:858-865.

87. Wong JB, Sonnenberg FA, Salem DN et al. Myocardial revascularization for chronic stable angina: Analysis of the role of percutaneous transluminal coronary angioplasty based on data available in 1989. Ann Intern Med 1990; 113:852-871.

88. Katz DA, Cronenwett JL. The cost effectiveness of early surgery versus watchful waiting in the management of small abdominal aortic aneurysms. J Vasc Surg 1994; 19:980-991. 